\title{
ASSOCICIATED FACTORS OF CONSTIPATION AMONG PARKINSON OLDER PATIENTS
}

\author{
Nguyen Ngoc Tam ${ }^{1,2}$, Nguyen Phuong Linh² and Nguyen Trung Anh ${ }^{1,2,}$ \\ ${ }^{1}$ National Geriatric Hospital \\ ${ }^{2}$ Hanoi Medical University
}

This cross-sectional study aimed to investigate the factors associated with constipation among elderly patients with Parkinson's disease (PD). The participants were recruited from the National Geriatric Hospital between July to September 2020. Constipation was diagnosed by using Bristol stool classification and Rome IV criteria. A total of 133 Parkinson older patients were enrolled in the study. In multivariable regression model, increased odds of constipation were significantly associated with low water consumption (adjusted OR 4.55), low vegetable consumption (adjusted OR 6.16) and dependent activities of daily living $(A D L)$ (adjusted OR 3.98). ADL needs to be regularly assessed and water and vegetable consumption should be closely monitored in older PD patients in order to improve health and reduce risk of constipation.

Keywords: Dependence; developing countries, associated factors

\section{INTRODUCTION}

Parkinson's disease (PD) is a neurodegenerative disease most often found in older people. Constipation is one of the main and disabling non-motor symptoms in patients with Parkinson's disease, with prevalence varies widely, ranging from $24.6 \%$ to $63 \%$ in a 2015 study by Fasano et al. or from $7 \%$ to $71 \%$ in a 2017 study by Knudsen et al. ${ }^{1,2}$ The wide ranges of prevalence of constipation in PD were mainly due to the different diagnostic criteria.

Several factors contribute to constipation among people with PD. Previous study showed that people recently diagnosed with PD were more likely to have reduced anal sphincter

Corresponding author: Nguyen Trung Anh,

Hanoi Medical University

Email: trunganhvlk@gmail.com

Received: 19/03/2021

Accepted: 20/05/2021 pressure, ${ }^{3}$ which suggested the anal sphincter might be unable to contract, or might relax instead of contracting. Individual-level factors associated with chronic constipation reported in the literature include ethnicity, lifestyle ${ }^{4}$ level of physical activity, diet, ${ }^{5}$ prescribed and illicit drug use, and genetic factors, although the effect of each of these has not been examined systematically.

Few study addressed the topic of constipation and its associated factors in Parkinson patients. ${ }^{6}$ This study aimed to describe the prevalence of constipation and investigate factors with associated constipation among elderly PD patients in Vietnam.

\section{METHODS}

\section{Research subjects}

Participants were recruited from the National Geriatric Hospital in Hanoi, Vietnam.

The inclusion criteria were (1) aged 60 years 
old and older and (2) diagnosis of Parkinson disease using MDS criteria without exclusion criteria in Outpatient Department.

Patients with the following were excluded from the study: (1) structural gastrointestinal abnormalities (including abdominal mass, tumors, and colorectal polyposis); (2) history of colorectal disease; (3) pharmacological treatments potentially affecting bowel motility and defecation (such as antidepressants, spasmolytics, or opioids); (4) history of psychological disease; (5) inability to communicate or underwent the physical examination; or (6) refusal to participate in the study.

\section{Method}

Study design: A cross -sectional study was conducted on 133 older Parkinson patients.

Time: July to September 2020.

Location: National Geriatric Hospital, Hanoi, Vietnam.

Variables and data collection:

Diagnosis of constipation

Constipation was diagnosed using the Bristol Stool Form Scale. Stools with separate hard lumps were classified as type 1 ; stools with sausage-shaped but lumply were classified as type 2; and 5 other types.

Functional constipation was diagnosed using Rome IV criteria. To be diagnosed with function al constipation, participants must satisfy 3 criteria in Table 1 in the prior 3 months, with symptom onset at least 6 months prior to diagnosis.

\section{Table 1. Rome IV criteria for the Diagnosis of functional constipation ${ }^{7}$}

Onset of constipation symptoms at least 6 months before diagnosis. Must met the three criteria below in the past 3 months

I. Two or more of the following criteria must be present:

a. Straining with $>25 \%$ of defecations

b. Lumpy or hard stools with $>25 \%$ of defecations

i. $\quad$ Bristol stool form types 1 and 2

c. Sensation of incomplete evacuation with $>25 \%$ of defecations

d. Sensation of anorectal onstruction/blockage with $>25 \%$ of defecations

e. Manual maneuvers required with $>25 \%$ of defecations

i. Eg, digital evacuations, support for the pelvic floor

f. Fewer than 3 spontaneous defecations per week

II. Loose stools are rare without administration of laxatives

III. Insufficient criteria for irritable bowel syndrome

Data on factors associated with constipation

Factors associated with constipation were assessed using a questionnaire administered by faceto-face interview by trained researchers. Data collected include:

- Daily consumption of water (water, milk, broth...): $\geq 1500 \mathrm{ml} /$ day or $<1500 \mathrm{ml} /$ day 
- Daily vegetable consumption: $1 / 2$ bowl, or equivalently $80 \mathrm{~g}$.

- Risk of fall: test of up and go was used to assess risk of fall. The participant stood up upon therapist's command, walked 3 meters, turned around, walked back to the chair and sat down. Those who took $\geq 14$ seconds to complete the sequence of actions were considered to have high risk of fall.

- Physical activity (PA) level was assessed using the International Physical Activity Questionnaire short form. A total of less than 600 METs -minutes/week was defined as low physical activity level.

- Nutritional status was assessed using the Mini Nutrition Assessment-short form questionnaire which had 6 questions. Scores between $0-7$ points were categorized as malnourished.

- Sarcopenia was assessed using the SARC-F questionnaire which had 5 items: strength, assistance with walking, rising from chair, climbing stairs and falls. A total score of $\geq$ 4 indicated sarcopenia.

- Dependence of activities of daily living (ADL) was assessed using the ADL scale and the Instruments Activities of Daily Living (IADL) scale

\section{Data analysis}

Data was entered, coded and analysed using Statistical Package for Social Science (SPSS) software (version 22). Characteristics of the partcipants were reported using descriptive statistics with frequency, percentage, and mean. Chi-square tests were used to perform comparisons between groups. Statistical significance was accepted at $p<0.05$. Need to add how ORs were obtained.

\section{Ethics}

Study participants were informed clearly about the purpose of the study, and they were willing to participate in the study. Study tool did not involve sensitive or intimate information, and did not affect the participants' emotion. Collected data was used for research with the aim of improving the health of community and no other purposes.

\section{RESULTS}

There was no statistically significant difference in the distribution of constipation between male and female participants $(p=$ 0.77 ). At the age of 70 or over, there were 42 patients with constipation; under the age of 70 , the constipation patients accounted for $64.3 \%$. There was no statistically significant difference in the proportion of those with constipation between age groups $(p=0.61)$.

Participants who had low PA level and water consumption of less than $1500 \mathrm{ml} /$ day were more likely to have constipation than the those with high PA level $(p=0.03$ and $p<0.01$, respectively).

There was significant association between risk of fall and constipation with $p=0.029$. There was significant association between physical function and constipation, $p=0.027$ 
Table 2. The relationship between constipation and some related factors among Parkinson older patients

\begin{tabular}{|c|c|c|c|c|c|}
\hline \multirow[t]{2}{*}{ Characteristics } & \multicolumn{2}{|c|}{$\begin{array}{l}\text { Parkinson patients } \\
\text { with constipation } \\
\qquad(n=87)\end{array}$} & \multicolumn{2}{|c|}{$\begin{array}{l}\text { Parkinson patients } \\
\text { without constipation } \\
\qquad(\mathrm{n}=46)\end{array}$} & \multirow[t]{2}{*}{ P-value } \\
\hline & $\mathbf{n}$ & $\%$ & $\mathbf{n}$ & $\%$ & \\
\hline Age $($ year $) \geq 70$ years & 42 & 48.3 & 21 & 45.7 & 0.77 \\
\hline Female & 49 & 56.3 & 28 & 60.9 & 0.61 \\
\hline Drink Water $<1500 \mathrm{ml} \mathrm{ml/day}$ & 58 & 66.7 & 10 & 21.7 & $<0.001$ \\
\hline Vegetable ( $\leq 160 \mathrm{~g} /$ day $)$ & 55 & 63.2 & 11 & 23.9 & $<0.001$ \\
\hline High risk of fall & 55 & 63.2 & 20 & 43.5 & 0.029 \\
\hline Low level physical activity & 47 & 54.0 & 16 & 34.8 & 0.03 \\
\hline Malnourished & 16 & 18.4 & 7 & 15.2 & 0.645 \\
\hline Having Sarcopeina & 67 & 77.0 & 25 & 54.3 & 0.007 \\
\hline ADL dependent & 61 & 70.1 & 14 & 30.4 & $<0.001$ \\
\hline IADL dependent & 57 & 65.5 & 21 & 45.7 & 0.027 \\
\hline
\end{tabular}

Multivariable logistic regression model revealed that higher odds of constipation was independently associated with water consumption of less than $1500 \mathrm{ml} /$ day $(\mathrm{OR}=3.34,95 \% \mathrm{Cl}: 1.67-11.27$ ), vegetable consumption of $\leq 160 \mathrm{~g} /$ day $(\mathrm{OR}=6.16,95 \% \mathrm{Cl}: 2.17-17.4)$, and being dependent on others for $\mathrm{ADL}(\mathrm{OR}=3.98,95 \% \mathrm{Cl}: 1.31$ - 12.04).

Table 3. Multivariable logistic regression: related factors with constipation in older Parkinson patients

\begin{tabular}{|c|c|c|c|c|}
\hline \multicolumn{2}{|c|}{ Factors } & \multirow{2}{*}{$\begin{array}{c}\text { OR } \\
1\end{array}$} & \multirow[t]{2}{*}{$\begin{array}{c}\text { 95\% Confident } \\
\text { interval }\end{array}$} & \multirow[t]{2}{*}{$P$ value } \\
\hline & $<70$ years & & & \\
\hline rige & $\geq 70$ years & 1.01 & $0.38-2.72$ & 0.98 \\
\hline \multirow{2}{*}{ Gender } & Male & 1 & & \\
\hline & Female & 10.63 & $0.22-1.74$ & 0.37 \\
\hline \multirow{2}{*}{ PA level } & Not low & 1 & & \\
\hline & Low level & 1.38 & $0.48-3.94$ & 0.55 \\
\hline \multirow{2}{*}{ Water } & $\geq 1500 \mathrm{ml} /$ day & 1 & & \\
\hline & $<1500 \mathrm{ml} /$ day & 4.55 & $1.68-12.3$ & 0.003 \\
\hline \multirow{2}{*}{ Vegetable } & > 160 g/day & 1 & & \\
\hline & $\leq 160$ g/day & 6.16 & $2.17-17.48$ & 0.001 \\
\hline
\end{tabular}




\begin{tabular}{llccc}
\hline & \multicolumn{1}{l}{ Factors } & OR & $\begin{array}{c}\text { 95\% Confident } \\
\text { interval }\end{array}$ & P value \\
\hline \multirow{2}{*}{ Risk of fall } & High risk of fall & 1 & & \\
\cline { 2 - 5 } & Low risk of fall & 1.23 & $0.42-3.62$ & 0.71 \\
\hline \multirow{2}{*}{ Nutritional status } & Malnourished & 1 & & \\
\cline { 2 - 5 } & Normal & 0.62 & $0.17-2.29$ & 0.48 \\
\hline \multirow{2}{*}{ Sarcopenia } & Normal & 1 & & \\
\hline \multirow{2}{*}{ ADL } & Predict sarcopenia & 2.01 & $0.66-6.14$ & 0.014 \\
\hline \multirow{2}{*}{ IADL } & Independent & 1 & & \\
\cline { 2 - 5 } & Dependent & 3.98 & $1.31-12.04$ & 0.38 \\
\hline
\end{tabular}

Age, gender, physical activity level, risk of fall, nutrition, sarcopenia, and IADL had no significant association with increased odds of constipation.

\section{DISCUSSION}

We observed a significant association between low water consumption and having constipation $(p<0.01)$. In other research of $M$ Anti also referred that functional constipation was affected can significantly enhanced by increasing fluid intake to $1.5-2.0$ liters/day. ${ }^{8}$ Although, another study by Shen et al. in 2019 showed that the amount of water consumption was significantly associated an with an increased risk of constipation in univariate analysis, but not in multivariate analysis. ${ }^{5}$

We also observed those who had 1 bowl $(160 \mathrm{~g})$ or less of vegetable per day had increased odds of constipation ( $p=0.001$ ). This finding is consistent with a recent study by Shen et al. in 2019 which found lower dietary fiber intake was associated with a greater risk of constipation. ${ }^{5}$ Similarly, in 2016, Yang et al. reported a correlation between diet habits and constipation among elderly in Beijin region. Constipation in the elderly of the Beijing region was closely related to diet habits, and the likelihood of having constipation significantly decreased with high staple foods intake and fish and high dietary fibers (fruits and vegetables) consumption. ${ }^{9}$ It was suggested the influence of dietary factors on constipation because food choices might easily reflect preferences directly as a result of constipation. However, these were findings from cross-sectional studies, a clinical trial on this field is required.

We found a significant association between activity daily level and having constipation ( $p$ $<0.05$ ). The analysis showed that those who were dependent on others for ADL were 3.98 times more likely to have constipation compared to independent people (95\% Cl:1.31 - 12.04, $P=0.014)$. Previously, in 2019, Gustafsson et al. reported people with a higher activity daily level scores were at decreased risk of constipation. ${ }^{10}$ This result can be explained by the fact that increasing activities help increase bowel movement and therefore may prevent constipation. 


\section{CONCLUSION}

Factors associated with higher odds of constipation in elderly PD patients were low water consumption, low vegetable consumption and ADL dependence.

\section{REFERENCES}

1. Fasano A, Visanji NP, Liu LW, Lang AE, Pfeiffer RF. Gastrointestinal dysfunction in Parkinson's disease. The Lancet Neurology. 2015; 14(6): 625 - 639.

2. Knudsen K, Krogh K, Østergaard K, Borghammer P. Constipation in Parkinson's disease: subjective symptoms, objective markers, and new perspectives. Movement Disorders. 2017;32(1):94-105.

3. Sung IK. Classification and treatment of constipation. The Korean journal of gastroenterology= Taehan Sohwagi Hakhoe chi. 2008; 51(1): 4-10.

4. Camilleri M, Ford AC, Mawe GM, et al. Chronic constipation. Nature reviews Disease primers. 2017;3(1):1-19.

5. Shen L, Huang C, Lu X, Xu X, Jiang Z, Zhu C. Lower dietary fibre intake, but not total water consumption, is associated with constipation: a population-based analysis. Journal of Human Nutrition and Dietetics. 2019; 32(4): 422-431.

6. Colosimo C. Nonmotor presentations of multiple system atrophy. Nature Reviews Neurology. 2011; 7(5): 295-298.

7. Lacy BE, Mearin F, Chang L, et al. Bowel disorders. Gastroenterology. 2016; 150(6): 1393-1407. e1395.

8. Anti M, Lamazza A, Pignataro G, et al. Water supplementation enhances the effect of high-fiber diet on stool frequency and laxative consumption in adult patients with functional constipation. Hepatogastroenterology. 1998; 45: 727-732.

9. Yang XJ, Zhang $\mathrm{M}$, Zhu H-M, et al. Epidemiological study: Correlation between diet habits and constipation among elderly in Beijing region. World journal of gastroenterology. 2016; 22(39): 8806.

10. Gustafsson $M$, Lämås $K$, Isaksson $U$, Sandman P-O, Lövheim H. Constipation and laxative use among people living in nursing homes in 2007 and 2013. BMC geriatrics. 2019; 19(1): 1-7. 